\title{
Adapting to the Living Space in the First Interior Design Studio
}

\author{
Pinar Sezginalp \\ Ozyegin University, Faculty of Architecture and Design, Istanbul, Turkey \\ Selin Ust \\ Ozyegin University, Faculty of Architecture and Design, Istanbul, Turkey
}

Received: April 28th 2021, Revised: June 5th 2021, Accepted: June 17th 2021.

Refer: Sezginalp, P., Ust, S., (2021), Adapting to the Living Space in the First Interior Design Studio, Journal of Design Studio, V.3, N.1, pp 97-106,

P. Sezginalp ORCID:,0000-0002-5389-1981 S. Ust ORCID: 0000-0003-4197-7793

DOI: $10.46474 /$ jds. 929495 https://doi.org/10.46474/jds.929495

\begin{abstract}
The case study will examine online and face-to-face learning experiences of the two different groups of students who have never been enrolled in an interior design studio, where they see their classmates and encounter an "interior architecture" project as a problem for the first time. As the "living spaces" were the main problematic of this design studio, the interaction, the time management in design development, means of representation, inputs and outputs of the studio, perception of space and scale were the main parameters that differed and varied within separate learning environments, and will be read through the feedback of the students.
\end{abstract}

Keywords: Interior Architecture Studio Education, Living Space Design, In-studio design education, Online Design Education.

\section{Behind the Scenes Calculations of the First Interior Design Studio ${ }^{1}$}

Interior architecture and environmental design education is a studio-based learning process that requires a certain time period and continuity within itself. In Özyeğin University's Faculty of Architecture and Design, department of Interior Architecture and Environmental Design, the education initiates with solving living-space requirements; followed with workplaces, retail, educational, hospitality, healthcare, exhibition, food and beverage spaces; and ends with refunctioning industrial or cultural heritage spaces. The relationship between the space and occupants is aimed to be constructed with an increasingly-complex nature in the curriculum. The first studio experience of the interior architecture and environmental design students is the architectural design studio where they are enrolled together with students in the department of architecture for the first two semesters of their academic life. ${ }^{2}$ After succeeding these architectural design studios, students of the department experience the interior design studio for the first time in their second year. The instructors and the rest of the students of the department are introduced. This first interior design studio can be inevitably defined as an opportunity to help students adapt to the contexts of interior space and interior architecture, by focusing on living and dwelling space problem solving - as it is the utmost relevant context which they already know from daily basis.

\footnotetext{
${ }^{1}$ This study will be grasping the case-studies of INAR 201 interior design studios that were given in fall and spring semesters of 2018-2019 academic year and fall semester of 2020-2021 academic year.

${ }^{2}$ The architectural design studios that are given under ARCH 101 and ARCH 102 course codes.
} 


\section{Journal of \\ Design Studio}

v:3 n:1 July 2021

This study will be examining two design studio cases, each given in separate academic semesters, and presented with variable inputs: Such as the profiles of the occupants, project sites and program requirements. The first studio case that will be investigated is from the fall semester of the 2018-2019 academic year where the learning environment was the physical space of design studios in the campus. The latter studio case is the fall semester of the 2020-2021 academic year, which was initiated and completed as an online design studio.

In the first studio that we will be focusing on, students were given an imaginary load-bearing structure that is located on a steep and vegetated empty plot of a demolished traditional mansion in the district of Moda of İstanbul, Şair Nefi Street. The problem was designing an accommodation unit for expats: A single traveller and two parents who are taking care of their two children aged between 3 and 11. This unit needed to include private and semiprivate/common spaces for these two types of occupant profile. Named "a short stay accommodation unit in Moda", the studio was completed as a face-to-face design studio.

In the second studio case, students were to create an imaginary load-bearing structure and a remaining stone wall from a prior residence that was located on an empty plot in Çanakkale Babakale. The problem was to provide a living space for a craftsperson, her/his partner and their children aged 8 years old, referring to these imaginary and remaining structures on the plot. The project name was "living with the craft". The students were free to choose which craft the occupant would be busy with. Living space of a craftsperson is often an interplay between the very characteristics of the act of creation and personal life (Bayraktaroğlu, 2020). The program needed an atelier/workshop, a common area for the guests and a private space for the family to dwell. The studio was completed as an online design studio.

The urgency for referring to the given imaginary structures without depending on them while "extending" from them and forming volumes using "fixed interior components" in order to address the needs of the occupants was notified as the main "output" to the students in both studio cases. The pattern of both studios was processing through a conceptual idea that is abstract yet glimpsing a physicality. This conceptual idea was the derivation point of the design solutions of living spaces and the subspaces that are dependent on these living spaces, evaluated with the requirements of privately and commonly occupied spaces, extended from and referring to the given structures. Students commenced their design processes by doing a thorough research on the extent of the project and its requirements, along with the historical, sociological context of the project site, and exemplary cases within the global context. With the guidance of their research, they were expected to generate a "design idea" that would be fixed throughout their design process. The design studio problems through the education of interior architecture could only be solved with the extents and references of an abstract "design idea" which was introduced to the students in this studio for the first time: In each space, all of the components of interior architecture like the fixed and movable furniture and lighting have to be designed in unity, in light of this design idea. The designed space is aimed to be an outcome of the coexistence of the findings about the history of the space and its location, the occupant(s) of the space, the requirements of the program and the research, under the light of an "anchor" that helps to develop the individual design-vocabulary of each student. Therefore, this "anchor" which was taught as the "design idea", becomes a habit for the students when they get into their professional lives after graduating, for reflecting a consistent story and authenticity within their design.

The acquisitions, differences and the learning outputs of the two design studios will be presented in this study: The collective one, where the studio instructor and other students are in a studio space in the campus, and, the latter where the students and the studio instructor are only engaged through the computer screen in their private spaces, mostly 


\section{Journal of \\ Design Studio}

v:3 n:1 July 2021

residences. $^{3} \quad$ The feedback gathered from interviews that were held with students will be considered within the evaluation of the study. ${ }^{4}$ The interwoven form of production and evaluation, together with the perception of space, scale and conduct of representation is the fundamental clause of this first interior design studio. Therefore, the reflections of different learning environments on the living-space solutions will be shared.

\section{Traces of the Studio Through the} Dialogues: The Remaining and the Vanished Design studios differ from standard classes due to their communication means and the nature of student learning. Cuff (1991) declares that the design studios are not solely work spaces: a design studio is a space where the living and studying activities intersect, therefore, it bears a similarity with a "home-office" approach. Studios are the spaces where both the course hours and the off-the-course hours are actively and densely used with "interaction". The immediate transformation from a physical learning environment to a virtual one turns the studios into "classes", as the course schedule started to define when the learning community should be online and offline.

The interviews held with the students who started and accomplished the first interior design studio face-to-face showed that the campus environment has a positive impact on their learning experience. Except the dialogues between students and the studio instructor within the studio hours, the studying hours when the students are alone with their projects or together with their peers support the progress of their project. In addition, the condition of different departments occupying the same space not only provides an environment for interchanging knowledge among the interior architecture students and the instructors, but also among those from other disciplines, which makes the studio learning environment an interdisciplinary one. Mutual occupation of the space defines the studio as an open learning space where each participant is in a dialogue with each other. Kvan (2001) states that; students succeed in learning when they work together on a problem, therefore an online design studio offers them an opportunity to learn across the boundaries of the physical studio. However, according to the findings of this research, it is apparent that: By shifting the studio space into a virtual one, not only the interaction between the students studying different disciplines has remarkably decreased, but also the interaction between the students within the same studio became limited as the studio instructor had to orient the students to embark on a dialogue. It is known that students limit communication when they do not know and trust each other (Richardson et al., 2012; Swan \& Shih, 2005; Tu \& McIsaac, 2002; Kvan, 2001). Therefore, whether it is a face-toface or a virtual studio education, it is more than natural to experience a remarkable decrease of the dialogues between the students, since it is the very first interior design studio of their academic life and they were not introduced to each other beforehand.

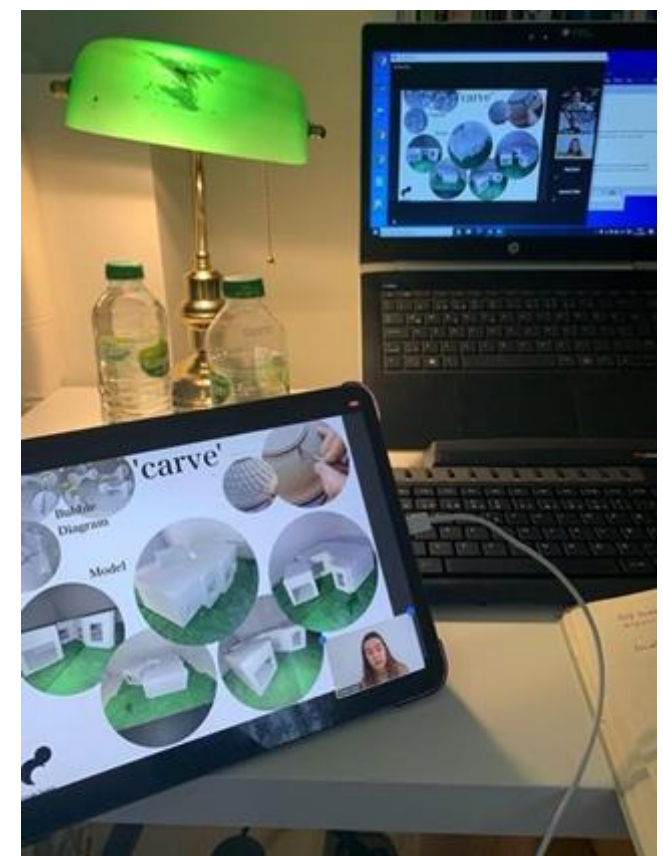

Figure 1: A view from the side of the studio instructor during the online studio

\footnotetext{
${ }^{3}$ There were rare exceptions where a few students had to connect to the online design studios from public spaces like restaurants or cafes due to problems with their internet connection, in some cases the students were connecting from the offices of their parents, if they continued working outside their home.

${ }^{4}$ The quantity of the interviewees was 22 in total, where 11 students who successfully passed each studio case of this research.
} 


\section{Journal of \\ Design Studio}

v:3 n:1 July 2021

The importance of face to face communication stood out during the interviews held with the students enrolled in the studios with the two different learning environments. The bond that was created via verbal expression/language, without gestures, facial expressions and eye contact, was replaced by a high level of effort in relating the non-design-related spaces ${ }^{5}$ with the design (Fig. 1). The dialogue between the student (the less-experienced junior designer) and the studio instructor faced the danger of shifting from a "reciprocally-fed" learning process to a more "didactic" one with the involvement of the screen in-between these two subjects: The producer (student) and the evaluator (instructor). Consequently, the quality of these reciprocal-feedbacks between the student and the instructor during the studio decreased dramatically. Initiating and sustaining a dialogue without the abovementioned contacts became totally dependent on the initiative of the student. Along with the weather conditions and infrastructural maintenance, the non-verbal bond that was created in face-to-face studio education fluctuated due to the quality of the internet connection, the computer and the camera of the student and the instructor. The equal conditions of the university campus as a democratic space for each individual became unequal and unstable, as education shifted to an extension of the "living space" or "home" where possibilities and impossibilities can be experienced together.

The interviews with the students who started and accomplished their interior design studio face-to-face (the first case of this study) showed that: The architectural drawings, sketches and mock-up design models that the studio instructor sketched, drew, scribbled, edited and used to suggest something were the most effective feedback conducts, while the students were trying to make progress with their design problems together with the other students in the same studio space (Fig. 2). During off-campus hours, while studying in their living spaces, these students had the chance to manually access these representational conducts created by the instructors: The students found it highly valuable for their design process. These easily accessible and "palpable" traces remained as drawings and the models were positive forms of learning medium, as they were the visual recordings of the in-studio critiques. Whereas, in the online studio case; the critiques were forwarded via virtual drawings on screens,

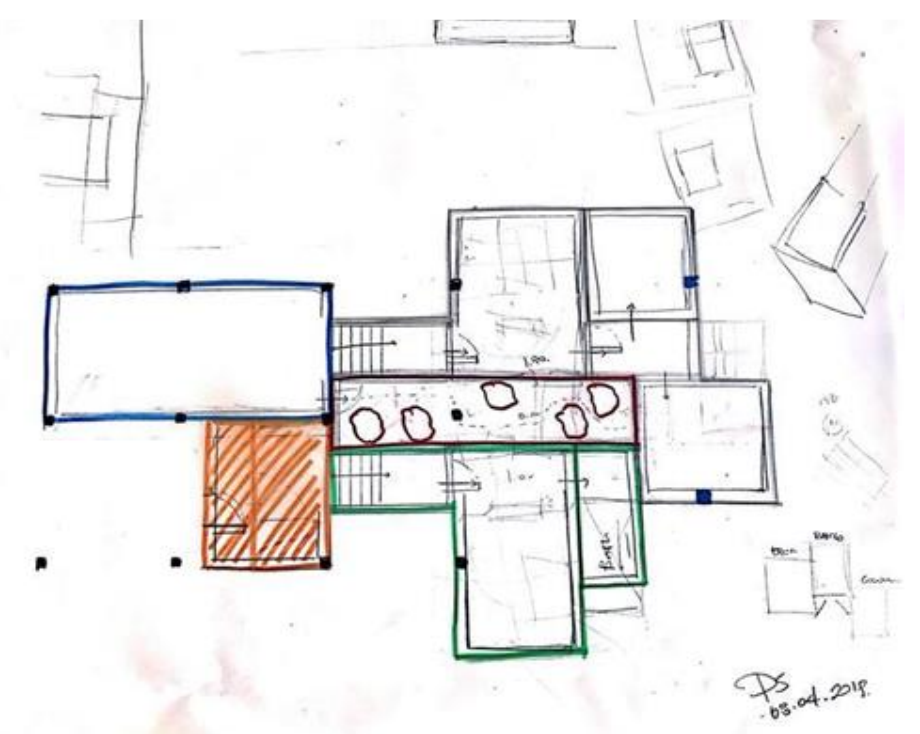

Figure 2: Sketch traces of the studio instructor drawn during in-studio critique that was kept as a souvenir by the students (Bilge Ökten archive)

\footnotetext{
${ }^{5}$ Zoom, Google Meet, Microsoft Teams software programs are mentioned here.
} 


\section{Journal of \\ Design Studio}

v:3 n:1 July 2021
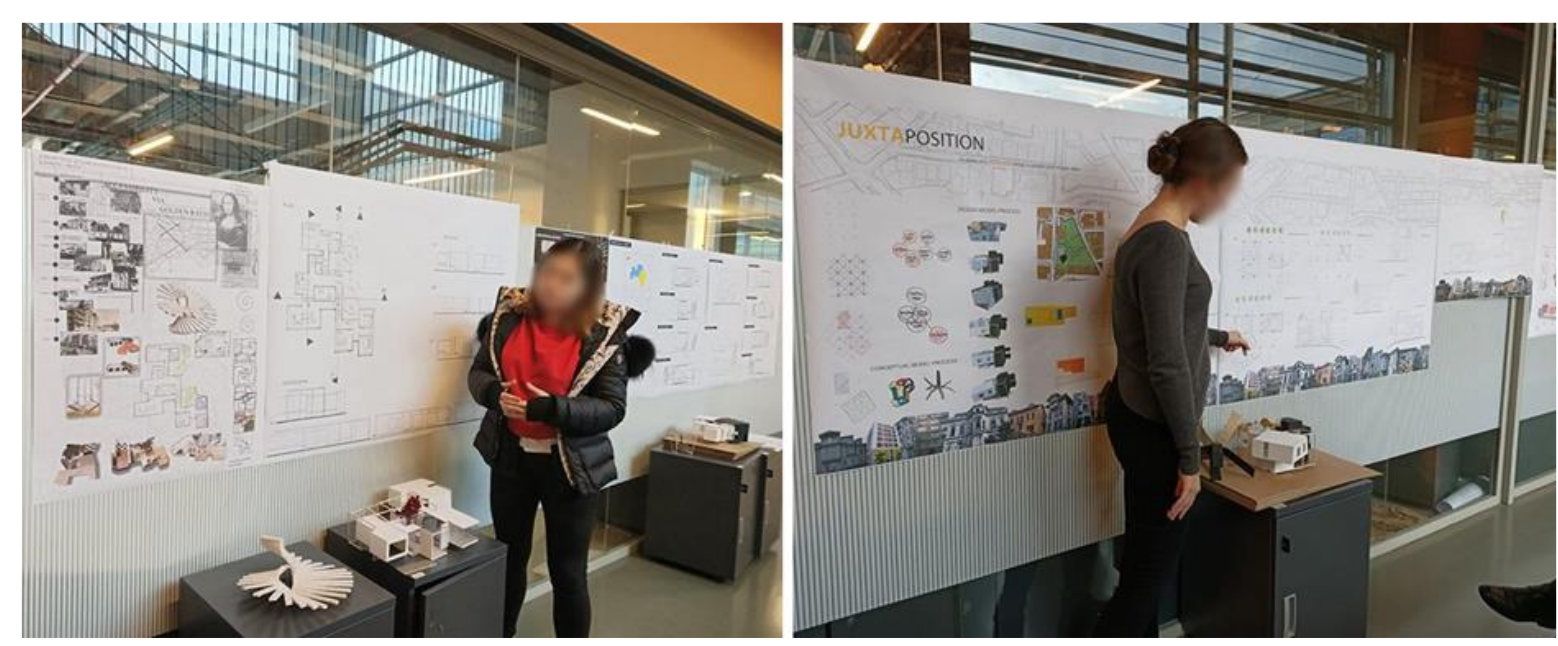

Figure 3: A capture from the final jury evaluation of the first interior design studio

traditional methods of verbally structured communication and brainstorming lost their functionality. The "palpable drawings and models" that were the outcome of reciprocal interaction shifted to "virtual screen images". As a result, the feedback outputs from face to face and online studio experiences were decomposed as "analogue" and "digital".

The distinguishing mark between the two modes of interior design studio education is the different trajectories of the dialogues: Face-toface dialogues progress via manually produced drawings whereas the online one takes off from the screen. The praxis of in-semester studio problem solving was carried on firstly starting with sketches and then with a certain scale architectural drawing placed on a paper in the face to face studio. According to the students, this habit of manually producing representational forms has been continued in the beginning of design problem solving, even though the students pursued their latter studio praxis with computational representations. On the contrary, students in online education courses started discovering supplementary representation tools surprisingly quickly, as the prior conducts vanished with the immediate shift: This was an opportunity to make themselves adapted to today's technology. Some research indicates that online design education can help students to facilitate their creative process and representation skills
(Broadfoot \& Bennett 2003; Waks 2001). The absence of the paper manifested as an opportunity for the practice of digital representation production and the timemanagement of this practice. In other words, paper shifted to the screen, mockup model shifted to the virtual model.

The praxis of timing was also transformed, as the learning space of the interior design studio education shifted. Parameters, such as, the preparation time to commute to the campus from the houses or dormitory rooms and vice versa, adjusting the studying time before the critiques so there would be enough time for printing representations, were essentialities of face to face design studios (Ust, 2021). As another crucial parameter, the time management of the students who were dwelling in the city-center was especially difficult since the campus of Özyeğin University is located far from the city-center. Among the interviewed students who experienced online studio education positively the "gaining of time" via online education was emphasized. They expressed that the former time-period that they had to spend on their daily needs, including the commute, was shifted to a "surplus and valuable" time-period within which they can improve their architectural representations and make progress on their designs. Therefore, it is inevitable to agree with Saghafi, Franz \& Crowther (2012) on the benefits of digital tools 


\section{Journal of \\ Design Studio \\ v:3 n:1 July 2021}

as they argue that it would save costs for publishing information and presenting resources with more multimedia facilities and higher quality. On the contrary, several students stated that the studio education became much harder as they had to be in their "living space" for their education: Those students said that they could not concentrate on the design problem in their "comfort zones", and they often found themselves enjoying quality-time activities. Thus, they pointed to a lack of productivity in their new working environments. To summarize, during the living space design problems, effective time management skills can vary according to individual characteristics, but regardless the learning environment is an actual design studio space or a virtual one.

The juries can be defined as the most crucial segment of interior architecture and environmental design education. In face to face education, juries are the open-door occasions that all departmental and/or faculty instructors and students can participate in, in which the students present their projects and get different feedback for improving their design problem solving: Therefore, juries are a collective learning experiences (Fig. 3). Symbolically important, juries are also the occasions where the students improve their verbal presentation skills, which can naturally be defined as a rehearsal for their professional lives. The opendoor mode of the juries eventually became limited due to the online education, so, the juries shifted to practices of possibilities of the occupied living spaces for both the instructor and the students (Fig. 4). The obvious contribution of the online-juries is: Invited jury members, regardless the coordinates in which they live, enrich the students' projects with their varied opinions and comments. However, the representational sheets shifted to "pixels" where the perception of scale vanished: The architectural representations became the whole virtual image whatever could be fit onto the screen at that moment. Investigating the details of the projects on the screen required more effort and careful-attention in the online juries. Therefore, the students uploaded their presentation sheets a few days prior to the jury so that the jury members were able to examine the submissions and evaluate them before the jury. This evaluation brought the supplementary need for a short video where the students express themselves and explain their design process. The input of the jury experiences in the two different environments varies. Interviewed students often expressed a feeling of pressure to explain their projects

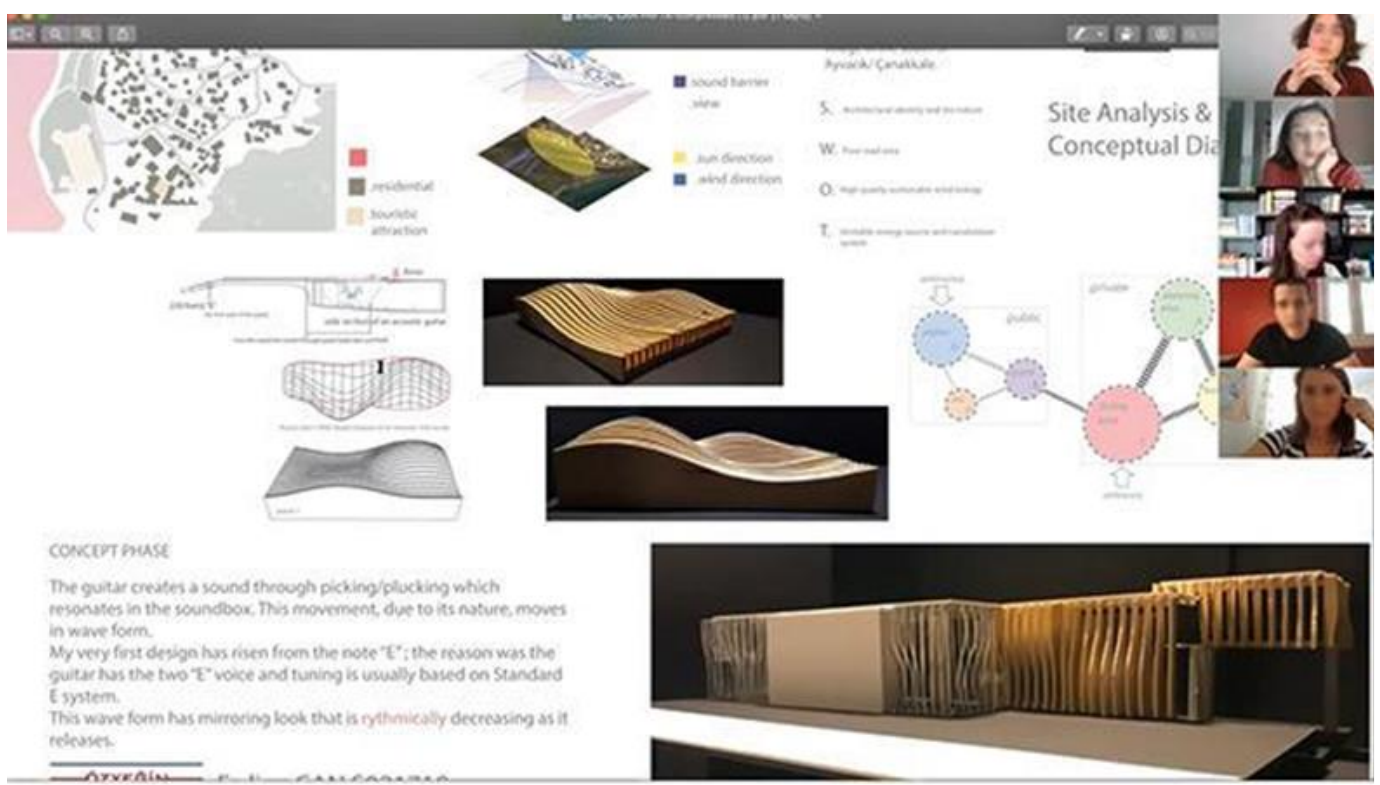

Figure 4: The online jury experience: A view from the final jury of first interior design studio of 2020-2021 fall semester 


\section{Journal of \\ Design Studio}

v:3 n:1 July 2021
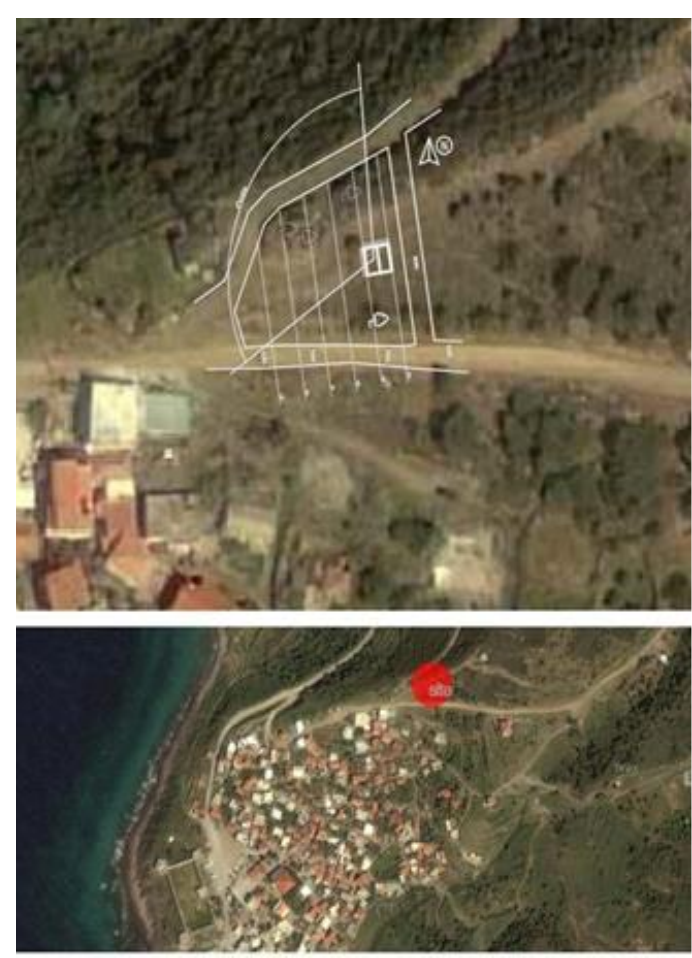

Figure 5: Traces of the study on the project location in the online interior design studio

effectively and consistently within a short period of time, after the long and difficult process of preparation for the juries. The feedback about uploading the pre-recorded videos for pre-evaluation of the jury members was positive, as these videos were supplementary for their online jury commentary as well. Interviewed students drew attention to the fact that these videos dissolved the possibility of being incapable of explaining the projects: The pre-recorded videos decreased the pressure of the jury experience, and helped overcome the jury stress and anxiety. To summarize, the experience of presenting the printed and organized representational sheets just a couple of steps in front of the observers shifted with the new format of juries and "momentary traces" vanished.

Interior design studios take off with research studies on the natural, historical, social and cultural patterns of the project location, in order to grasp and evaluate those issues. In the first case of this study, "a short-stay accommodation unit in Moda" project, students made observations and analysis of the location during and after the site-visit to Moda and its environs. These observations are of the utmost importance for the project, as they are the ones which define and form the "design idea," which is the core of the project. A photograph, a handdrawn sketch or a voice recording taken in the project site could be the derivation point of their analysis and design idea. Whereas, in the online studio where the project was "living with a craft", students could not visit the project site in Babakale. Relating to the project site became difficult for the students in this case. Each student tried to perceive the meaning and reality of the project location with mutual conducts ${ }^{6}$. A lack of observations and analysis pushed them to thoroughly research oral history, therefore many students constructed their design ideas and projects over a literature review (Fig. 5).

Living-space projects aim to respond to the fundamental necessities of daily life in residences. Challenging the prior knowledge of students about the dimensions within the userand-need based volumes of daily life in dwellings, and, designing new "spatial borders" via forgetting the "coded" spatial borders in society, these projects hold a foundational place in interior architecture education. Once a place is called a "home", it does not only address a dwelling that protects from physical conditions, it is also the place that one belongs to (Douglas \& Smith, 2001). The concepts of dwelling, house, privacy and territoriality are thought through the personal and common spaces in the design progress of the projects. To initiate this process, students grasp human-behaviour space components as a whole within the given scenarios.

The relationship between the interior components, the spaces deviated from these components and the occupants can only be evaluated with a perception of scale through basic measurements. The typology of the living space for the students was only experienced as an occupant. Therefore, they were naturally ignorant of the often-faced obstacles within

\footnotetext{
${ }^{6}$ Google maps, Yandex maps
} 


\section{Journal of \\ Design Studio}

v:3 n:1 July 2021

these spaces and their awareness grew in the process of the living-space design problem in the studio. It is of utmost value for the students to relate themselves with the practice of interior architecture through the context of interior space for the first time, as the bond between the apprenticeship and the profession becomes stronger with the help of this studio experience. The issue of accomplishing the living-space design studio from their actual living space was considered an opportunity for the online studio students. While studying on their projects, the students questioned the ergonomic principles that have to be supported by anthropometric data in the actual living-space they experience at that very moment, and proposed solutions from that space they occupied. On the contrary, in face-to-face education, the students had to deal with the time-management of the "observation" of these anthropometric data of the living-space in the relatively short time period when they were occupying their homes or dormitory rooms. One of the targets of this design project was to determine the daily needs of living space for the occupant(s) and transfer the extension of these needs via measuring. Therefore, the students of face-to-face education expressed that they evaluated their living space as a laboratory of freshly-found data, dimensions, proportions and occupation modes - as the actual living space of those students was somewhere to which they arrived right after the studio study hour.

Measuring and applying the "valid" dimensions "at the very moment" of experiencing and occupying the living-space were amongst the most positive inputs of online interior design studio education, whereby the students were adapted to the virtual studio experience. Whereas in the face-to-face design studio education, more labour is needed for students to get adapted to designing the interior space components of the living-space and its needs.

\section{Evaluation}

Design studio can be defined as the space where the uncertainty and uniqueness in design education are exposed as well as the space where the students focus on the problems that emerge, improve different ways of understanding, reflect their personal experiences into knowledge and propose design solutions (Schön, 1985; Schön \& Wiggins, 1992, Salama, 2015). Regardless of the learning environment (online or face to face); Broadfoot and Bennett (2003) identified four conditions for an effective design education: 1 . learning by doing experience 2 . focus on process 3 . collaborative learning 4 . one-to-one dialogue between instructor and student.

The living-space problem, as the very first interior design studio experience within the interior architecture and environmental design education, aims to teach the students that the interior space is related to something beyond the constructed interior components: It aims to teach that the space is only formed by the extensions of the necessary movements within the required program. Identical to the Raumplan solution of Adolf Loos, the needs of the interior space are addressed through thinking with "volumes", rather than depending the interior space design solely on the plans and sections. By means of this way of design thinking, students are encouraged to re-think the coded and "already adapted" daily life activities such as, studying, sleeping, dining, food preparation, reading, laying down and taking clothes off from the wardrobe/cloth storage. In other words, students "tailor" the living space for the occupants of their projects.

Without a doubt, it is an efficient approach to initiate the design studio education with the problem solving of living space design, as it makes the students bond more with their education into the profession in Özyeğin University's Faculty of Architecture and Design, department of Interior Architecture and Environmental Design. In the time period of solving the living space problem, we observed that some of the outputs between face to face and online education in terms of the quality equivalence were not matching. While students of online education improved the speed and practice of producing representations of their homes, they had to sacrifice the traditional onthe-paper praxis of many important conducts of architectural representation skills, such as scale, depth/lineweight and proportion. Compared to 


\section{Journal of \\ Design Studio}

v:3 n:1 July 2021

face-to-face education where the students accomplished their design education in the studios on campus, the time management skilllearning seemed to vary per individual student in the online education.

The remaining traces from the prior critiques and juries were easily palpable, as the papers and mock-up models were manually accessible for the students in face-to-face education. This concept of palpability was another inequivalent output. On the contrary, the students, who were enrolled in the online education were fed only by the traces of a virtual pen on a screen, without witnessing any gestures, expressions, eye contacts and the hand and body coordination of the lecturer during the praxis of sketching and drawing: The dialogues were constructed in a "verbal yet contactless" form. From the beginning until the end of the "sketching" of the studio instructor, students had the chance to observe the whole experience as part of face-to-face education. Yet, the students in online education had to retain the freshness of their design-process memory with only "finished" virtual images. This condition can be evaluated as a positive outcome, as the students were feeling "pushed" to take more initiative to be in continuous contact with the instructor, and as the instructor had relatively less intervention in the design process.

Last but not least, it is of utmost importance to remember that the online education experience that has been investigated in this study is not a transformation to a virtual design studio, but a "transformation to a virtual design studio in extraordinary conditions". Beyond all mentioned concerns, there were two main determining issues. The first one was the physical and psychological conditions of both the students and the design studio instructors, the latter was the financial possibilities and limits. Investigating via the feedback of the students within the contexts of space, time, representation and dialogue, this study underlines the importance of the prospective potential of an initially-alienated situation of many concepts and the vanished indispensability of traditional studio learning. It is an in-between designing process of making the students adapted and not-adapted to the living space: Designing a living-space from a living-space, solving the borders of interior space through the extensions of imaginary users, learning the interior space design over the ambiguous intersection of an invisible subject yet a visible final product.

\section{Acknowledgement:}

We would like to thank our interior architecture and environmental design students for their participation and enthusiasm in this study. We would also like to extend our gratitude to Lecturer Seda Dönmez and Research Assistant Ezgi Çiçek for being our colleagues and sharing our passion during the studio classes.

\section{References:}

Bayraktaroğlu S., (2020). Actors of rural innovation: Bamboo craft initiatives from Northeast India. In L. S. Andersen (Eds.), Rural Areas: An Overview (pp.145-191). New York: NOVA Science Publishers Inc.

Broadfoot, O. \& Bennett, R., (2003). Design Studios: Online? Comparing Traditional Faceto-face Design Studio Education with Modern Internet-based Design Studios. Apple University Consortium Academic and Developers Conference Proceedings. Sydney, 9-21.

Cuff, D., (1991). Architecture: The Story of Practice. Cambridge: MIT Press.

Jara, C., (1995). Adolf Loos's "Raumplan" Theory, Journal of Architectural education (1984- ) 48(3), 185-201

Kvan, T., (2001) The Pedagogy of Virtual Design Studios. Automation in Construction, 10(3), 345-354.

Porteous, D., \& Smith, S., (2001). Domicide: The Global Destruction of Home. Canada: McGill-Queen's University.

Richardson, J. C., Arbaugh, J. B., ClevelandInnes, M., Ice, P., Swan, K. P., \& Garrison, D. R., (2012). Using the community of inquiry framework to inform effective instructional 
design. In L. Moller, J. B. Huett (Eds.), The next generation of distance education (pp. 97-125). Springer, Boston, MA.

Salama, A. M., (2015). New Trends in Architectural Education: Designing the Design Studio. North Carolina, Tailored Text and Unlimited Potential Publishing.

Saghafi, M., Franz, J., \& Crowther, P., (2012). Perceptions of physical versus virtual design studio education. Archnet-IJAR, 6(1), 6-22.

Schön, D. A., (1985). The design studio: An exploration of its traditions and potentials. London: RIBA Publications.

Schön, D. A. \& Wiggins, G., (1992). Kinds of Seeing and Their Functions in Designing. Design Studies, 13(2), 135-156.

Swan, K., \& Shih, L., (2005). On the nature and development of social presence in online course discussions. Journal of Asynchronous learning networks, 9(3), 115-136.

Tu, C., \& McIsaac, M., (2002). The Relationship Of Social Presence And Interaction in Online Classes. The American Journal of Distance Education, 16(3), 131-150.

Ust, S., (2021). Emergency Remote Teaching in Interior Architecture: A Necessary Shift. In K. Enomoto, R. Warner \& C. Nygaard (Eds.), Teaching and Learning Innovations in Higher Education (pp.109-127). Oxfordshire: Libri Publishing.

Waks, L. J., (2001). Donald Schon's philosophy of design and design education, International Journal of Technology and Design Education, Vol. 11(1), 37-51. 